\title{
Prosthetic Valve Thrombosis: About 205 Patients
}

Redhouane Boukarroucha*, Nadjet Massikh, Samiha Chérif, Redha Lakehal, Soumaya Bendjaballah, Baya Aziza, Farid Aimer, Rabeh Bouharagua, Chourouk Rakouk, Karima Bouguerra and Abdelmalek Brahami

Cardiac Surgery Department, EHS Erriadh, Constantine, Algeria

*Corresponding author: Redhouane Boukarroucha, Cardiac Surgery Department, EHS Erriadh, Constantine, Algeria, E-mail: redbouker2001@yahoo.fr Rec date: Mar 15, 2017; Acc date: Apr 27, 2017; Pub date: May 02, 2017

Copyright: @ 2017 Boukarroucha R, et al. This is an open-access article distributed under the terms of the Creative Commons Attribution License, which permits unrestricted use, distribution, and reproduction in any medium, provided the original author and source are credited.

\begin{abstract}
Background: The prosthetic heart valve thrombosis (PVT) is a life-threatening complication of mechanical valve prosthesis. It can be attributed more frequently to inadequate anticoagulant therapy. In the aortic and mitral position, reported incidences vary widely from $0.5 \%$ to $6 \%$ per patient-year, and are highest in the mitral position and up to $20 \%$ in tricuspid valve prosthesis. Medical therapy (Thrombolysis) has emerged as an alternative therapy in high-risk surgical patients, considering that surgical prosthetic valve replacement is related to significant operative morbidity and mortality rates. The purpose of this study is to present a single-center experience of 205 consecutive patients hospitalized between 2000 and 2016.
\end{abstract}

Methods: From 2000 to 2016, 205 consecutive patients were hospitalized in our center for mechanical prosthetic valve thrombosis (PVT). The diagnosis of PVT was mainly assessed by echocardiography and/or fluoroscopy. There were 41 men and 164 women aged between 07 to 75 years. Prosthetic valve location was mitral in 191 patients, tricuspid in 05 , aortic in 8 and mitro-tricuspid in one case. Predisposing causes of MVT were: poor compliance with warfarin, pregnancy or unknown. The interval from first operation to valve thrombosis was from 1 day to 38 years. Delay from first symptoms to hospitalization ranged from 1 to 4 months.

The diagnosis was an incidental finding during an echocardiography, on the basis of a subacute increase in the transvalvular mean gradient seen due to thrombotic obstruction on transthoracic echocardiography and was confirmed by transesophageal echocardiography. First clinical symptoms were reported as systemic emboli, progressive exertional dyspnea (NYHA II to III-IV), muffled opening or closing sounds of the prosthetic valve, left heart failure, stroke, and cardiogenic shock. Transthoracic echocardiography is the diagnostic tool often used to evaluate a patient with valve prosthesis, when there is suspicion of PVT, and also is useful in the follow-up of patients during thrombolysis. Fluoroscopy was complementary. Anticoagulation regimen was inadequate, recently stopped or incorrectly conducted.

Results: There were two groups, the first group (A) comprised of 135 patients have been operated with cardiopulmonary bypass (CPB) (prosthetic replacement or declotting and excision of pannus). It is an emergency surgery in 101 patients. In this group, we deplore 18 (13.5\%). 70 patients underwent medical treatment (heparin, oral anticoagulants and aspirin) on clinical, sonographic and under strict supervision in a hospital and some external purposes for a period of 07 days at 6 months. For the non-operated group, all patients have unlocked their prothesis; we deplored 05 deaths $(7.14 \%)$ (hemorrhagic stroke, left and right ventricle dysfunction).

Conclusion: PVT remains a serious complication of mechanical heart valve prosthetic with high morbidity and mortality despite aggressive treatment by thrombolysis and/or surgery. Surgery treatment should be the preferred therapeutic modality for most patients with PVT.

Thrombolysis, followed by heparin, warfarin, and aspirin is advised for high-risk surgical candidates without hemodynamic instability under strict echocardiographic survey. Because of the high risk of thromboembolism during thrombolysis for left sided PVT.

For certain category of patients, medical therapy (thrombolysis anticoagulation++aspirin) may be offered in highrisk surgical patients, this with the consent of patients on medical and surgical rigorous monitoring and evaluating the operational risk compared to the risk of progression under medical treatment.

Keywords: Prosthetic valve thrombosis; Thrombolysis; Surgery; Introduction Complications; Treatment; Outcome; Emboli; Pannus

Rheumatic arthritis (RA) remains a public health problem in our country and in undeveloped countries, due to the prevalence of its main complication (rheumatic heart disease). Surgery of postrheumatic valvulopathy is a predominant proportion of cardiac surgery activity, despite all efforts to prevent RA and infectious 
Page 2 of 5

endocarditis. Treatment is often a mechanical replacement, thromboembolic complications. In spite of the progress made in the design of new generations of mechanical prosthesis and the right prescription of anti-vitamin $\mathrm{K}$ therapy, prosthesis thrombosis of the heart remains a dreaded complication.

Thromboembolic and hemorrhagic accidents are the main complications of cardiac mechanical prosthesis (Thrombo-embolic peripheral accidents, Thrombosis of prosthesis (Occlusive or nonocclusive thrombosis)).

The rate of thrombo-embolic events is $2 \%$ patient-years in aortic position and $2.5 \%$ patient-years-in mitral position for bileaflet valve (4.16). The rate increases to $2.1 \%$ patient-years in the aortic position and $3.6 \%$ patient-years in the mitral position for the ball valve (Figures $1-3)[1]$.

\section{Problematic}

Although therapeutic management of thrombosis is currently well codified ACC/AHA and ESC guidelines [2-4], it remains problematic in certain circumstances like thrombosis and pregnancy, early postoperative thrombosis and recurrent thrombosis.

The objective of this study is multiple:

1)Interest in early diagnosis for better therapeutic management.

2)Define a therapeutic strategy for heart prosthesis thromboses.

3)Better prevention of these accidents.

In this article we present the epidemiological, clinical features, imaging diagnosis, and treatment of 205 patients hospitalized in our department for prosthesis thrombosis and especially for a certain population whose medical treatment was instituted with favourable results.

\section{Materials and Patients}

\begin{tabular}{|l|l|l|l|l|}
\hline \multicolumn{3}{|c|}{ wannual Incidence } \\
\hline
\end{tabular}

Table 1: Number of patients operated under cardiopulmonary bypass.
This is a retrospective analytical descriptive study of patients admitted from January 2000 to June 2016 for cardiac valvular thrombosis. Of a total of 6133 open-heart interventions, 205 patients were hospitalized for heart prosthetic thrombosis.

The mitral position of thrombosis predominates (186 mitral valve, tricuspid valve and 08 aortic valve and mitro-tricuspid thrombosis).

\begin{tabular}{|l|l|l|l|l|}
\hline & $\begin{array}{l}\text { Total } \\
\text { implant }\end{array}$ & $\begin{array}{l}\text { Total } \\
\text { thrombosis }\end{array}$ & $\begin{array}{l}\text { Patients } \\
\text { operated in } \\
\text { our center }\end{array}$ & $\begin{array}{l}\text { Patients } \\
\text { operated in } \\
\text { other } \\
\text { centers }\end{array}$ \\
\hline Mitral Valve & 2963 & 191 & $\begin{array}{l}119+1 \\
(04.01 \%)\end{array}$ & 72 \\
\hline Aortic Valve & 1736 & 8 & $4(00.46 \%)$ & 4 \\
\hline $\begin{array}{l}\text { Tricuspid } \\
\text { Valve }\end{array}$ & 43 & 5 & $4+1(11.62 \%)$ & 1 \\
\hline Total & 5014 & 205 & $128(04.08 \%)$ & 78 \\
\hline
\end{tabular}

Table 2: Set of thrombosis and origin of patients.

\section{Results}

The femal sex predominates with a sex ratio of 0.25 (164 women and $41 \mathrm{men}$ ). The age of patients varied from 07 to 75 years. 28 patients had pregnancy during different age (17.39\%).

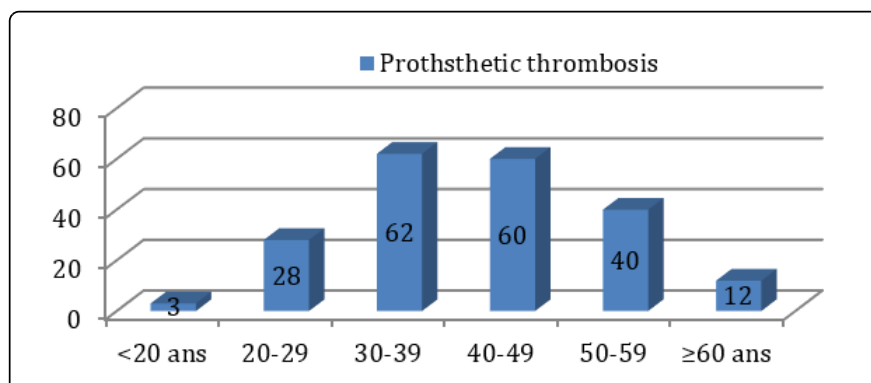

Figure 2: Age of patients.

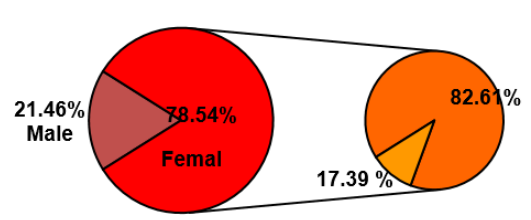

Figure 3: Sex of patients.

Analysis of the preoperative data a made it possible to record the following elements:

the implantation delay of the mechanical valve replacement/ thrombosis varied from 01 days to 38 years. The onset of symptoms at diagnosis varied from 01 day to 4 months (Figure 4). 


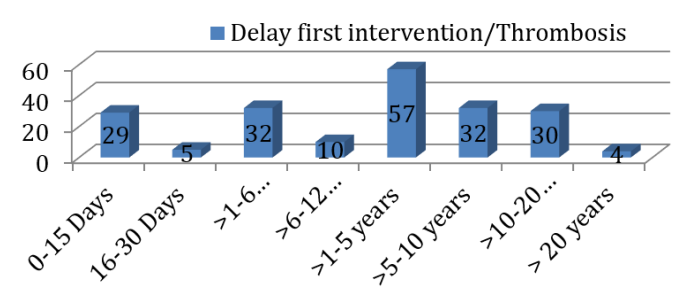

Figure 4: Prosthesis implantation/thrombosis delay.

The circumstances of occurrence are multiple. In 33 patients, this was postoperative thrombosis. For 34 (16.58\%) patients with thrombosis occurred within the first 30 days. Distance from the intervention (163 Patients): 99 (48.29\%) patients over 1 month up to 05 years and $64(31.21 \%)$ patients over 5 years of intervention. 151 patients were under antivitamin $\mathrm{K}$ and for the rest under heparin. Various symptoms: The diagnosis of echocardiographic findings in front of the increase in the trans valvular mean gradient or symptoms (dyspnea) or complications (systemic embolism), changes in auscultation of valve sounds, heart failure, stroke or cardiogenic shock. Quality of anticoagulation treatment before thrombotic accident was difficult to assess (Figure 5).

\begin{tabular}{|l|c|c|}
\hline Symptoms & Operated Group & Non operated Group \\
\hline NYHA II & 38 & 13 \\
\hline NYHA III & 38 & 49 \\
\hline NYHA IV & 56 & 05 \\
\hline Pulmonary oedema & 08 & 03 \\
\hline Cardiac shock & 03 & 00 \\
\hline Echocardiography & 00 & 00 \\
\hline ATE & 03 & 04 \\
\hline
\end{tabular}

Figure 5: Symptoms of patients.

Heart rate: in the operated group, 91/135 patients were in sinus regular rhythm versus $46 / 70$ in the unoperated group. The cardiothoracic index varied between 0.5 and 0.74 in the operated group and from 0.43 to 0.68 in the unoperated group. Trans-thoracic and/or trans-oesophageal echocardiography associated with scopy were the means of diagnosis and follow-up.

In the operated group (135 patients), aortic valve thrombosis: mean gradient was $57.1 \mathrm{~mm} \mathrm{Hg}$ (37-72), Tricuspid valve thrombosis: mean gradient was $16.13 \mathrm{~mm} \mathrm{Hg}(13-19.3)$.

In the non-operated group (70 patients), aortic valve thrombosis: mean gradient was $23.7 \mathrm{~mm} \mathrm{Hg} \mathrm{Max} \mathrm{42.56,} \mathrm{Tricuspid} \mathrm{valve} \mathrm{thrombosis:}$ mean gradient was $11.99 \mathrm{~mm} \mathrm{Hg}(10.8-14.45)$ (Figure 6).

135 patients underwent surgery on cardiopulmonary bypass (CPB) (65.86\%), 34 patients in emergency deferral (failure of medical treatment) and 101 patients in emergency (delay of less than 24 hours) (Table 1). The approach of the heart by a vertical median sternotomy with aorto-bicaval cannulation 133 femoro-bicaval patients in 02 patients.

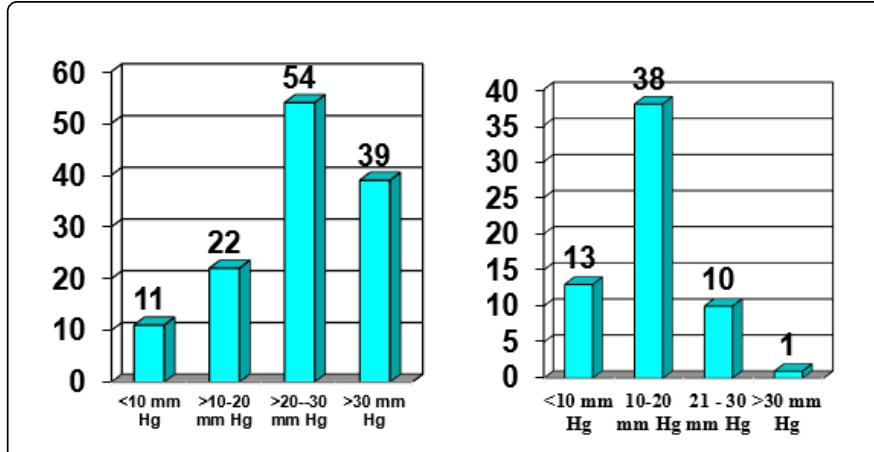

Figure 6: Mitral mean prosthetic gradient.

Myocardial protection was by cold crystalloid cardioplegia in 118 patients, by cold blood cardioplegia in 15 patients and under assistance circulatory in 02 patients.

The surgical treatment was:

1)Mitral surgery: (Valve replacement: 113 patients, Thrombectomy: 15 patients, Fibrous pannus removal: 01 patient).

2)Aortic surgery: Mechanical valve replacement in five patients.

3)Tricuspid Surgery: Mechanical Valve Replacement in Two Patients.

4)Mitro-tricuspid surgery: Biological valve replacement in one Patient.

Operational variables: Duration of aortic clamping: $61.22 \mathrm{mn}$ (16-155), Duration of CPB: $100.1 \mathrm{mn}$ (44-290), Duration of circulatory assistance: $26.81 \mathrm{mn}$ (9-168). In intensive care: The average duration of ventilation: (4-398) hours, stay in intensive care unit (ICU): 4.56 days (0-51), Inotropic+: 87/135 Patients, Average length of hospital stay: 19.5 days (1-68). Simple surgical suites 88 patients. In the operated group, there are 18 deaths out of 135 patients. Mortality is $13.3 \%$, date of death 11.4 days (0-34) and causes are varied (cardiopulmonary not be discharged: 01 cases, LV dysfunction: 05 cases, Severe rhythm (ventricular fibrillation): 02 cases, renal insufficiency: 04 cases, septic shock: 02 cases, haemorrhagic stroke: 02 cases and hypoxemia: 01 case). Complications were observed in the ICU or in the postoperative (31 in ICU and 23 in hospital). 07 abortions out of a total of twenty-two patients. Seventy patients underwent medical treatment (heparin, antivitamin $\mathrm{K}$ and aspirin) on clinical, ultrasound and rigorous monitoring criteria in hospitals and certain outpatients with duration of 07 days to 6 months. For the unoperated group, all patients unblocked their fins; 05 deaths $(7.14 \%)$ (haemorrhagic stroke, left and right ventricle dysfunction). Complications were observed in the ICU or postoperatively (06 patients). 02 abortions on a total of twenty-two patients (Table 2) [4].

\section{Discussion}

Recommendations for the management of prosthesis thrombosis are well defined by learned societies (ESC and ACC/AHA). Nevertheless, the management of the prosthesis thrombosis in our center poses several problems:

1)High incidence of prosthesis thrombosis. 
2)Redo in all patients (red, tridux or even quadridux) with these consequences (morbidity and mortality).

3)Medical treatment in certain cases, under certain conditions and under rigorous medical-surgical supervision. For what length of medical treatment (tolerable time from the institution of medical treatment until release).

4) What is the place of Thrombolysis?

5)In the situation of thrombosis and pregnancy, what therapeutic must be proposed?

6)What attitude to postoperative thrombosis?

\section{Choice of valvular substitute \& anticoagulant treatment}

In our practice the mechanical substitute is by far the most commonly implanted and this is in different valvular positions (Mechanical mitral valve: $93.65 \%$, mechanical aortic valve: $98.52 \%$, mechanical tricuspid valve: $71.42 \%$ ) and this due to the unavailability of the biological substitute, rejection by patient's reoperation).

In our series, a high incidence of thrombosis $(04.08 \%)$ is observed: (mitral valve: $04.01 \%$, aortic valve: $00.46 \%$, tricuspid valve: $11.62 \%$ ), this may be related to various reasons:

1) Choice of Patients for Mechanical substitute.

2) Socio-cultural and economic level.

3) Frequent mechanical substitution.

4) Replacement number>conservative treatment (post-RAA lesions) (95.05\%).

5) Quality of anticoagulant treatment (assiduity, difficulty of followup and relay).

There are two types of patients:

1) Hemodynamic instability: High morbi-mortality.

2) Hemodynamic stability: Low morbi-mortality.

The diagnosis of thrombosis must be premature: Functional symptoms of abrupt installation, in a valvular prosthesis wearer, must cause suspicion of valve thrombosis.

\section{Choice of therapy}

In the recommendations of the European Society of Cardiology, the management of prosthetic thrombosis depends on several factors (clinical stability, hemodynamic and ultrasound gradient and mobility of the fins) and distinguishes between obstructive thrombosis and non-obstructive thrombosis. According to ACC/AHA, the thromboses of the heart are distinguished from the thromboses of the right heart.

Choice of therapeutics: In our series, mechanical valve replacement is often performed: Mitral valve replacement in 113 patients (36 bioprothesis), Thrombectomy in 15 patients, Aortic valve replacement in 05 Patients, Tricuspid surgery in 02 Patients. Thrombectomy was the therapeutic choice despite the risk of rethrombosis, a risk that was raised in Roudaut's publication [5].

As for the thrombolysis, in our series, no patient benefited, two patients benefited from this therapeutic before their transfer to our center because both patients showed incomplete resolution and symptoms aggravation. In the ESC Guidelines:
1) Obstructive thrombosis of the left heart: Thrombolysis in a critical condition; the unavailability of surgery and in case of recent thrombosis and high operative risk in the absence of a critical situation.

2) Non-obstructive thrombosis of the left heart: at high surgical risk

3) ACC/AHA guidelines: Right thrombosis at failure of UFH.

4) ACC/AHA guidelines: Left thrombosis in case of recent thrombosis, NYHA I-II; Size $<0.8 \mathrm{~cm}^{2}$ and in case of failure of nonfractioned heparin.

5) Some authors recommend: Thrombolysis in the foreground in the absence of contraindications whatever the degree of obstruction; NYHA; size of the thrombus; reserving surgery in case of contraindication or failure of thrombolysis [6-10]. Others propose it in the event of signs of heart failure or in the absence of a surgical center: lower mortality/surgery [7-11].

6) Right thrombosis: thrombolysis; Left thrombosis: surgery especially in case of chronic obstruction or left thrombosis [5]. Fibrinolysis is proposed in case of critical condition associated with recent obstruction in case of emergency surgery or in case of contraindication to surgery (low flow, redux, respiratory insufficiency) [5].

Fibrinolysis in stable cases after transoesophageal echocardiographic examination (Absence of large thrombus [5], but the inconvenient were embolic accidents.

\section{Thrombosis and pregnancy}

Pregnancy in a valve carrier is a major risk of thromboembolic event, in our series, out of a total of 205 thromboses, 28 Patients were in gestation of different age (17.39\%). Twelve patients were operated on and six patients not operated (11.1\%), among the factors favoring the occurrence, the following factors were noted:

1. Rural population socio-cultural and economic level.

2. Non-availability of bio-prosthesis for women in reproductive age.

3. Non-availability and high cost of non-fractioned heparin for the relay.

4. Low molecular weight heparin: Absence of marketing authorization in our country.

5. Women's insistence of second pregnancy.

6. Gynecologist/Cardiologist Collaboration.

7. Management of the anticoagulation during gestation: Deliberate arrest; under dosage; inter-laboratory results variability.

8. Lack of a center specialized in the management of this type of patient. Hence the value of bioprosthesis in any woman wishing to become pregnant and maintain of AVK during pregnancy (ESC, ACC/AHA: $5 \mathrm{mg}$ ).

\section{Thrombotic recurrence}

Thrombotic recurrence is a rare and severe complication, depending on the initial accident. In our series, we observed 18 rethrombosis in a variable delay $(08.78 \%)$, the prognosis is more severe when it comes to rethrombosis associated with gestation, it is:

1) A second thrombosis in 16 patients, two patients received medical treatment, five patients with surgical treatment and seven patients with medical and surgical treatments. 
2) Third Thrombosis: 01 Patient (Surgery $\left.{ }^{\star} 3\right)$; First intervention: Mitral replacement.

3) Fourth Thrombosis: 01 Patient $\left(T_{R T} \mathrm{MDL}^{\star} 2+\right.$ Surgery$\left.{ }^{\star} 2\right)$; Primointervention: Double mitro-tricuspid mechanical replacement.

\section{Favourable factors:}

1) Availability of bio-prosthesis.

2) Relay quality (availability and cost of relay, follow-up of relay efficiency).

3) Predisposition to thrombosis (study of coagulation factors).

4) Other gestations with mechanical substitute.

What attitude to postoperative thrombosis?

A postoperative thrombosis is a serious complication, in our practice we had to manage 33 Patients (16.09\%).

The analysis of the patient files identified as favoring factors (Vice technique (Orientation of the fins, long and free ropes, inadequate anticoagulation, etc.), hence the interest of the prevention:

1) Surgical rigidity (preservation of the device under the valve).

2) Strict monitoring of anti-coagulation, especially in patients at risk (low cardiac output, ectasic GC, ACFA, Postpartum).

3) Regular clinical and ultrasound follow-up.

Finally, there is a pertinent question, what attitude should be adopted in the face of postoperative thrombosis? Two options: medical treatment/surgical treatment (morbidity and mortality) [12-14].

\section{Conclusion}

The zero risk of heart prosthesis thrombosis does not exist despite the use of AVK whatever the type of mechanical prosthesis [15]. The correct indication of the type of valvular substitute (priority is a conservative gesture on valve replacement), the quality of anticoagulant therapy and its follow-up. The judicious choice of the valvular substitute taking into account the patient (age, sex), his socioeconomic level and desire for pregnancy can reduce the risk of thromboembolism accidents.

«Prevention is better than cure», Hence the need to insist on: Prevention of rheumatic fever.

\section{References}

1. Leguerrier A, Flecher E, Fouquet $O$, and Lelong B (2009) Prothèses valvulaires cardiaques. EMC Cardiologie 4: 1-31.
2. Vahanian A, Alfieri O, Andreotti F, Antunes MJ, Baron-Esquivias G, et al. (2012) Guidelines on the management of valvular heart disease (version 2012), The Joint Task Force on the Management of Valvular Heart Disease of the European Society of Cardiology (ESC) and the European Association for Cardio-Thoracic Surgery (EACTS). Euro Heart J 33: 2451-2496.

3. Nishimura RA, Otto CM, Bonow RO, Carabello BA, Erwin JP et al. (2014) AHA/ACC Guideline for the Management of Patients With Valvular Heart Disease: A Report of the American College of Cardiology/ American Heart Association Task Force on Practice Guidelines. Circulation 129: E521-E643.

4. Edmunds LH Jr, Clark RE, Cohn LH, Grunkemeier GL, Miller DC, et al. (1996) Guidelines for reporting morbidity and mortality after cardiac valvular operations. Ad hoc liaison committee for standardizing definitions of prosthetic heart valve morbidity of the American association for thoracic surgery and the society of thoracic surgeons. J Thorac Cardiovasc Surg 112: 708-711.

5. Roudaut R, Roques X, Lafitte S, Choukroun E, Laborde N, et al. (2003) Surgery for prosthetic valve obstruction. A single center study of 136 patients. Eur J Cardiothorac Surg 24: 868-872.

6. Ca'ceres-Loriga FM (2008) Prosthetic valve thrombosis: is it time for a new consensus conference?. Euro J Echocardiography 9: 413-414.

7. Alpert J (2003) The thrombosed prosthetic valve. J Am Coll Cardiol 41: $659-660$.

8. Lengyel M, Vandor L (2001) The role of thrombolysis in the management ofleft-sided prosthetic valve thrombosis: a study of 85 cases diagnosed transesophageal echocardiography. J Heart Valve Dis 10: 636-649.

9. Lengyel M (2004) Management of prosthetic valve thrombosis. J Heart Valve Dis 13: $329-334$.

10. Lengyel M (2005) Thrombolysis should be regarded as first-line therapy for prosthetic valve thrombosis in the absence of contraindications. J Am Coll Cardiol 45: 325.

11. Van Kuilenburg JT, Verheugt FWA, Van Dijk APJ (2007) Prosthetic heart valve thrombosis, anticoagulation and pregnancy: a case report and review of literature. Netherlands Heart J 15: 306-309.

12. Buttard P, Bonnefoy E, Chevalier P, Marcaz PB, Robin J, et al. (1997) Mechanical cardiac valve thrombosis in patients in critical hemodynamic compromise. Eur J Cardiothorac Surg 11: 710-713.

13. Bollag L, Attenhofer Josta CH, Vogta PR, Linkab AZ, Ricklib H et al. (2001) Symptomatic mechanical heart valve thrombosis: high morbidity and mortality despite successful treatment options. Swiss Med Weekly 131: 109-116.

14. Horstkotte D, Burckhardt D (1995) Prosthetic valve thrombosis. J Heart Valve Dis 4: 141-153.

15. Charokopos N, Antonitsis P, Artemiou P, Rouska E, Foroulis C, et al. (2009) Acute mechanical prosthetic valve thrombosis after initiating oral anticoagulation therapy. Is bridging anticoagulation with heparin required? Interact Cardio Vasc Thorac Surg 9: 685-687. 